\title{
BENZENE EXPOSURE AMONG AUTO-REPAIR WORKERS FROM WORKPLACE AMBIENCE: A PIONEER STUDY FROM PAKISTAN
}

\author{
ATIF KAMAL and AUDIL RASHID \\ Pir Mehr Ali Shah Arid Agriculture University, Islamabad, Pakistan \\ Department of Environmental Sciences, Eco-Health Research Group
}

\begin{abstract}
Objectives: In Pakistan, the reports on benzene exposure among workers in chemical industries are almost non-existing due to limited research work in the field of exposure science. This study aimed to investigate such exposure in a widely adopted occupation in Rawalpindi city. Material and Methods: In this cross-sectional study, 60 blood samples ( $\mathrm{N}=20$ /group) of mechanics (MCs), spray painters (PNs) and control participants $(\mathrm{CN})$ were analyzed. The socio-economic and demographic information of workers and that of workplaces was documented using a short questionnaire. Results: We identified that the workers in spray-painting occupation are highly at risk of benzene exposure. The results showed that PNs were more at risk of exposure to benzene than MCs, and this exposure was significantly correlated with long working hours $(r=0.68, p<0.001)$. Moreover, there are several limitations in workplace setups, which need to be addressed in order to mitigate workers health risk in this occupation. In addition to the reckless use of chemicals, other identified predictors of exposure included active and passive smoking, poor workplace hygiene and substandard ventilation. Conclusions: To mitigate workplace exposure, it is necessary to reduce working hours and encourage regular use of self-protective equipments and adoption of proper hygiene in chemical workplaces.
\end{abstract}

Key words:

Pakistan, Benzene, Spray painters, Auto-repair workers, Rawalpindi, Blood

\section{INTRODUCTION}

Automobile manufacturing, repair stations, spray painting and other related workplaces are examples of automobilerelated occupations in Pakistan where workers face exposure to organic solvents to a great extent [1-3]. Among many environmental sources, benzene mostly arises from fuel vapors and gasoline which are used for degreasing and diluents at automobile mechanic work areas [4]. It is also present in the tobacco smoke. Petroleum comprises of $1-4 \%$ benzene as a component.

Occupationally, benzene exposure occurs in workplaces like refineries, garages, and paint manufacturing. Petrol stations are a cause of exposure and resulting cancer risk for the general population [5], and excessive risk of hematopoietic diseases in other subjects [6]. Benzene is a common component of petroleum products, and a known carcinogen. Workers involved in transportation of petroleum are known to bear high load of benzene in their biological fluids [7]. It is also reported that there exists a risk greater by $70 \%$ of leukemia for workers when they are exposed to $3.195 \mathrm{mg} / \mathrm{m}^{3}$ benzene (based on molecular weight of benzene, i.e., $78.11 \mathrm{~g} / \mathrm{mole}$ ) for 40 years. The allowable airborne level is $0.1 \mathrm{mg} / \mathrm{m}^{3}$ as recommended by NIOSH and ACGIH [8].

Received: January 23, 2014. Accepted: May 16, 2014.

Corresponding author: A. Kamal, Eco-Health Research Group, Department of Environmental Sciences, Pir Mehr Ali Shah Arid Agriculture University, Islamabad, Pakistan (e-mail: dr.atifkamal@yahoo.com). 
According to Kalnas and Teitelbaum [8], workplace hygiene is an important determinant of exposure. In workplaces, mere cleaning is not enough, but it requires that furniture, seating and resting places should also be thoroughly cleaned. Similarly, the surfaces of floors, walls and ceiling must be kept free from residues and waste storage receptacle must be used as a routine to improve the hygiene in workplaces. A recent study by the Health and Safety Executive [9] showed that shipyard painters were exposed to ethyl benzene and xylene, and that skin absorption was the dominant route of exposure among spray painters (PNs). Occupational surveillance and risk analysis for specific job responsibilities has enormous potential in risk identification and prevention of chemical exposure. In this context, studies have used demographic characteristics [10], because features like age, gender, body mass index (BMI), smoking status, consumption of contaminated food are important determinants of exposure surveillance. In the current study, the main focus was to evaluate the exposure to benzene among automotive workshop mechanics. It was also intended to identify the workplace and environmental predictors which could be considered potential risk factors for the health of the studied cohort.

\section{MATERIAL AND METHODS}

\section{Socio-demographic data}

In this study, frequent visits were made to the workplaces for blood sampling and visual monitoring [11]. Blood sampling and the acquisition of questionnaire data were performed on the same day and in the same place. The subjects were selected from the slums areas and main market areas of Rawalpindi city.

A multiple choice questionnaire was used to gain information on the socio-demographic status of workers and workplace environmental hygiene conditions. The workplace hygiene was ranked as 'good,' 'satisfactory' or 'poor' following pre-set criteria assigned to workplace floors, ceilings, walls and overall contamination at work areas. Evaluation of workplace criteria included an assessment of general maintenance and chemical handling, evidence of spills or residues, presence of exhaust facilities and overall conditions of walls, ceilings and floors, and air circulation across the work areas, all of which were recorded through the questionnaire as numerical rankings. The floors heavily contaminated with chemical residue and other debris were given the lowest rank (poor). Middle and highest ranks were given to those areas which were kept free of chemicals, to a great extent, and were maintained properly, i.e., there were separate working and storage areas with distinguished chemical disposal areas. Workplace furniture, walls and ceilings were ranked using similar criteria. The workers' use of self-protective equipments, like gloves, masks, respirators, etc. as self-safety protocol, was also recorded. Blood sampling was performed in a separate, least contaminated spot of the workplace.

\section{Sampling strategy}

Sampling sites were divided into control and exposed areas, from where 60 blood samples from 3 groups, $(N=20$ from each group, i.e., mechanics - MCs, spray painters - PNs and control participants - CNs) were collected. Control subjects were selected from persons with non-chemical occupations, who work indoors for similar hours, but in workplace conditions that are relatively free of chemicals. All the blood samples were taken during regular work hours. Sterile syringes, vacutanors, disposable gloves, alcoholic swabs and safety bandages were used every time to ensure safety and minimize sampling errors and chances of contaminations. From each participant, 3-4 ml of blood was taken from the antecubital vein and was immediately transferred into vacutanors. All the samples were immediately transferred to the analytical laboratory for further processing and storage. 


\section{Blood benzene analysis and quality control parameters}

All the steps of the extraction were standardized, with making every possible effort to avoid contamination and to observe good laboratory practices. Samples standard concentrations were prepared and analyzed according to a previously reported method [12-14]. Calibration standards were prepared by serial dilutions in acetonitrile, from the stock. The prepared standards $\left(100 \mu \mathrm{g} \times \mathrm{ml}^{-1}\right)$ were run a number of times; and the signal-to-noise ratio $(\mathrm{S} / \mathrm{N})$ method was used to determine the limit of detection (LOD, i.e., $0.003 \mu \mathrm{g} \times \mathrm{ml}^{-1}$ ) with an average $\mathrm{R}^{2}=0.99$. The method included 5-6 procedural blanks runs following the same number of standard samples runs to get the average value of baseline noise and the standard, respectively. The baseline was stabilized and a blank was run every time prior to the analysis. The method performance was evaluated by multiple analyses of control blood samples previously spiked with a standard containing the known concentration of benzene.

The control blood samples were spiked with known concentrations of the standard, and kept overnight for homogenization. The recovery efficiency of benzene ranged between 86 and $102.6 \%$, with a relative standard deviation (RSD) of \pm 16 . A 5-point calibration curve was drawn for quantification, and benzene in the samples was identified on the basis of respective retention times quantified on the basis of respective peak areas and expressed as $\mathrm{mg} \times \mathrm{I}^{-1}$.

\section{Statistical analysis}

Categorical variables were analyzed using the $\mathrm{Chi}^{2}$ test to observe the group-wise differences in socio-economic and demographic characteristics. Concentration of benzene in blood of different groups was compared by employing an independent sample t-test, while the associations between long-transformed laboratory data and questionnaire data (i.e., smoking status, work hours, etc.) were analyzed using the Pearson and Spearman correlation analyses. An $\alpha$-level of $p<0.05$ was considered as statistically significant. The principal component analysis (PCA) was conducted several times with a varimax rotation. The adequacy of sample sizes and the suitability of data for PCA analysis were evaluated, the correlations between items were also sufficient and large enough for PCA application (i.e., KMO = 0.76, Bartlett's test of sphericity $\left.\mathrm{Chi}^{2}=158.69, \mathrm{p}<0.001\right)$. Tabulation, correlation and graphical representation were carried out in Microsoft Excel spreadsheets, whereas other statistical analyses were performed using SPSS version 13.

\section{Ethics}

Only those subjects were recruited that were willing to participate and that were clearly informed about the purpose of investigations and expected outcomes. All subjects singed the questionnaire as their written consent. Sampling and logistic support for this research was granted by the ethical review committee of the University in collaboration with the Volunteer's Social Welfare Organization (VSWO) (registered under Social Welfare Act, 1961, Pakistan).

\section{RESULTS}

\section{Socio-economic and demographic characteristics of respondents}

The socio-demographic features of participants, i.e., MCs and PNs and the CNs group are summarized in Table 1. Spray painters had the lowest level of education and income $(\mathrm{p}<0.001)$ in comparison with the CNs group $(\mathrm{p}<0.001)$ (Table 1). No significant difference in age, height, and weight was observed among the 3 groups. During samples collection it was observed that none of the workers in the exposed groups (MCs and PNs) was equipped with any kind of self protective equipment. Among all the areas visited during the survey, only $10 \%$ had satisfactory hygiene, whereas $90 \%$ places were under 
Table 1. Personal characteristics and blood benzene data of the subjects in the exposed groups vs. the control group

\begin{tabular}{|c|c|c|c|c|c|}
\hline \multirow{3}{*}{ Variable } & \multirow{2}{*}{\multicolumn{2}{|c|}{ Exposed group }} & \multirow{3}{*}{ Control group } & \multicolumn{2}{|c|}{$\mathrm{p}$} \\
\hline & & & & \multirow{2}{*}{$\begin{array}{c}\text { PNs } \\
\text { vs. CNs }\end{array}$} & \multirow{2}{*}{$\begin{array}{c}\text { MCs } \\
\text { vs. CNs }\end{array}$} \\
\hline & spray painters & mechanics & & & \\
\hline Age (years) [M (25-75th)] & $27.5(25.3-29.0)$ & $28.1(25.25-30.8)$ & $26.85(22.3-29.7)$ & $0.51^{\mathrm{a}}$ & $0.21^{\mathrm{a}}$ \\
\hline Height $(\mathrm{cm})[\mathrm{M}(25-75$ th $)]$ & $171(165.0-176.0)$ & $170.6(165-173.7)$ & $171(164-176)$ & $0.77^{\mathrm{a}}$ & $1^{\mathrm{a}}$ \\
\hline Weight (kg) [M (25-75th)] & $61(56-62.8)$ & $58.5(55-62)$ & $59.5(55-65)$ & $0.84^{\mathrm{a}}$ & $0.67^{\mathrm{a}}$ \\
\hline BMI [M (25-75th)] & $18.9(18.2-20.3)$ & $19.05(18.4-20.7)$ & $19.1(18.2-20.9)$ & $0.88^{\mathrm{a}}$ & $0.92^{\mathrm{a}}$ \\
\hline Working (h/day) & $8 \pm 1.83$ & $8.5 \pm 1.42$ & $6 \pm 1.93$ & & \\
\hline \multicolumn{6}{|l|}{ Blood benzene concentration $\left(\mathrm{mg} \times \mathrm{l}^{-1}\right)$} \\
\hline $\mathrm{M}(25-75$ th $)$ & $0.28(0.09-0.88)$ & $0.11(0.01-0.79)$ & $0.05(0.01-0.25)$ & $0.028^{b}$ & $0.20^{\mathrm{b}}$ \\
\hline $\mathrm{M}(\min .-\max )$ & $0.86(0.43-3.60)^{*}$ & $0.51(0.23-1.30)$ & $0.18(0.2-0.87)$ & $\mathrm{r}=33^{\mathrm{c}}$ & \\
\hline Income rupees $\left(\times 10^{3}\right)[\mathrm{Me}(25-75$ th $)]$ & $8.5(6.50-11.50)$ & $8.5(8-10)$ & $14(12.3-16)$ & $<0.001^{\mathrm{a}}$ & $<0.001^{\mathrm{a}}$ \\
\hline \multicolumn{6}{|l|}{ Education $(\%)$} \\
\hline under-primary & $16(80)$ & $8(40)$ & $0(0)$ & $<0.001^{\mathrm{d}}$ & $<0.001^{\mathrm{d}}$ \\
\hline primary & $3(15)$ & $7(35)$ & $3(15)$ & & \\
\hline secondary & $1(5)$ & $4(20)$ & $12(60)$ & & \\
\hline higher-secondary & $0(0)$ & $1(5)$ & $5(25)$ & & \\
\hline \multicolumn{6}{|l|}{ Smoking status (\%) } \\
\hline non-smoker & $8(40)$ & $11(55)$ & $17(85)$ & $<0.005^{\mathrm{d}}$ & $0.225^{\mathrm{d}}$ \\
\hline smoker & $12(60)$ & $9(45)$ & $3(15)$ & & \\
\hline \multicolumn{6}{|l|}{ Smokers at home $(\%)$} \\
\hline no & $12(60)$ & $10(50)$ & $16(80)$ & $<0.150^{\mathrm{d}}$ & $<0.048^{\mathrm{d}}$ \\
\hline yes & $8(40)$ & $10(50)$ & $4(20)$ & & \\
\hline \multicolumn{6}{|l|}{ Workplace exhaust system (\%) } \\
\hline good & (0) & $0(0)$ & $3(15)$ & $<0.027^{\mathrm{d}}$ & $<0.027^{\mathrm{d}}$ \\
\hline satisfactory & $1(5)$ & $1(5)$ & $5(25)$ & & \\
\hline poor & $19(95)$ & $19(95)$ & $12(10)$ & & \\
\hline \multicolumn{6}{|l|}{ Workplace hygiene (\%) } \\
\hline good & $0(0)$ & $0(0)$ & $16(80)$ & $<0.001^{\mathrm{d}}$ & $<0.001^{\mathrm{d}}$ \\
\hline satisfactory & $1(5)$ & $3(15)$ & $4(20)$ & & \\
\hline poor & $19(95)$ & $17(85)$ & $0(0)$ & & \\
\hline
\end{tabular}

BMI - body mass index; MCs - mechanics; PNs - spray painters; CNs - control participants; BMI - body mass index; Me - median; M - mean; min. minimum value; max - maximum value.

* Significant at $=p<0.05$.

${ }^{\mathrm{a}}$ Independent sample t-test; ${ }^{\mathrm{b}}$ Mann Whitney's U-test; ${ }^{\mathrm{c}}$ Size of the effect; ${ }^{\mathrm{d}} \mathrm{Chi}^{2}$ analysis.

poor hygiene conditions (Table 1). The ventilation in the workplaces was generally poor, i.e., the quality of the exhaust systems was not very good. The comparative analysis of blood benzene concentration showed significantly higher concentrations in blood samples of PNs than $\mathrm{CNs}$ ( $\mathrm{p}<0.001$ ) (median: 0.28 and $0.05 \mathrm{mg} \times \mathrm{l}^{-1}$, respectively). 
The blood benzene levels were higher in PNs as compared to the MCs (i.e., 0.86 and $0.51 \mathrm{mg} \times \mathrm{l}^{-1}$, respectively), but the difference was non-significant.

When the data were split into smokers (SMs) and nonsmokers (nSMs), we observed significantly higher benzene levels among SMs than nSMs in all 3 groups ( $\mathrm{p}=<0.001,0.03$, and 0.14 for PNs, MCs and CNs, respectively). Log-transformed results of blood benzene showed a positive correlation between the blood benzene level and the work experience of exposed subjects $(r=0.62)$, a similar association of blood benzene was observed with workplace hygiene $(r=0.38)$, poor ventilation $(\mathrm{r}=0.43)$, working hours $(\mathrm{r}=0.68)$, smoking habit $(\mathrm{r}=0.49)$, and BMI $(\mathrm{r}=0.51)$ (Figure 1$)$. To identify significant predictors of blood benzene concentration, variables were entered into stepwise linear regression analysis, which showed daily work hours as a significant predictor (adjusted $\mathrm{R}^{2}=0.23$, 95\% CI: 0.12-0.33).

To reduce the dimensionality of data, PCA was used, which revealed 2 components collectively accounting for $65.6 \%$ of the data variability. Both components had initial eigenvalues over Kaiser's criterion (i.e., > 1) and hence provide sufficient support to use this approach for analyzing occupational characteristics (Table 2). The classification of principal components identifies 2 groups in the loading

Table 2. Factors loadings and variance explained by individual components in the principal component analysis

\begin{tabular}{lcc}
\hline \multirow{2}{*}{ Factor loading } & \multicolumn{2}{c}{ Principal component (PC) } \\
\cline { 2 - 3 } & PC-1 & PC-2 \\
\hline Blood benzene & - & 0.64 \\
Working hours & - & 0.66 \\
Smoking & - & 0.72 \\
Poor workplace hygiene & 0.86 & - \\
Poor workplace ventilation & 0.89 & - \\
Presence of smoker(s) at home & - & 0.73 \\
Lack of hazard awareness & 0.85 & - \\
Eigenvalues & 3.26 & 1.32 \\
Variance explained $(\%)$ & 46.70 & 18.97 \\
\hline
\end{tabular}

plot: the 1st component showed workplace features, while the 2nd component comprised personal characteristics of workers (Figure 2).

\section{DISCUSSION}

In developing countries, there are many chemical products still being used despite their well known adverse health outcomes. This study addressed benzene exposure among individuals as an indicator of health risk factors in occupational ambience. Since benzene exposure is considered one of the possible causes of morbidities among automobile workers including PNs [15], our investigation primarily focused on behavioral aspects of workers and conditions in the workplace that may increase chances of exposure and can be used to predict future health risks. Our results showed that workers in automotive repair spray-painting occupations generally have reckless behavior towards the usage of chemicals, because they have nominal education. We observed significantly higher blood benzene levels in automobile PNs than CNs (Table 1), which is attributable to skin absorption due to lack of practicing self-safety protocol and this fact is convincing because there can be significant absorption of benzene through skin, which depends upon the exposed skin area and the time of exposure. A strong correlation pertaining to our log-transformed data for blood benzene concentration in SMs helped us to identify smoking as the most apparent confounding factor among exposed groups. According to Weisel [16], inhalation exposures as well as benzene penetration through skin are most prominent routes of benzene exposure. It is also important to note that most of the painting tasks are preformed adjacent to the mechanical workstations; PNs were thus more exposed to organic solvents. In addition to the skin absorption of benzene, the occlusion, i.e., the trapping of the liquid between skin and clothing of the workers, may reduce the evaporation of trapped liquids and thus also facilitates the skin absorption. Such 

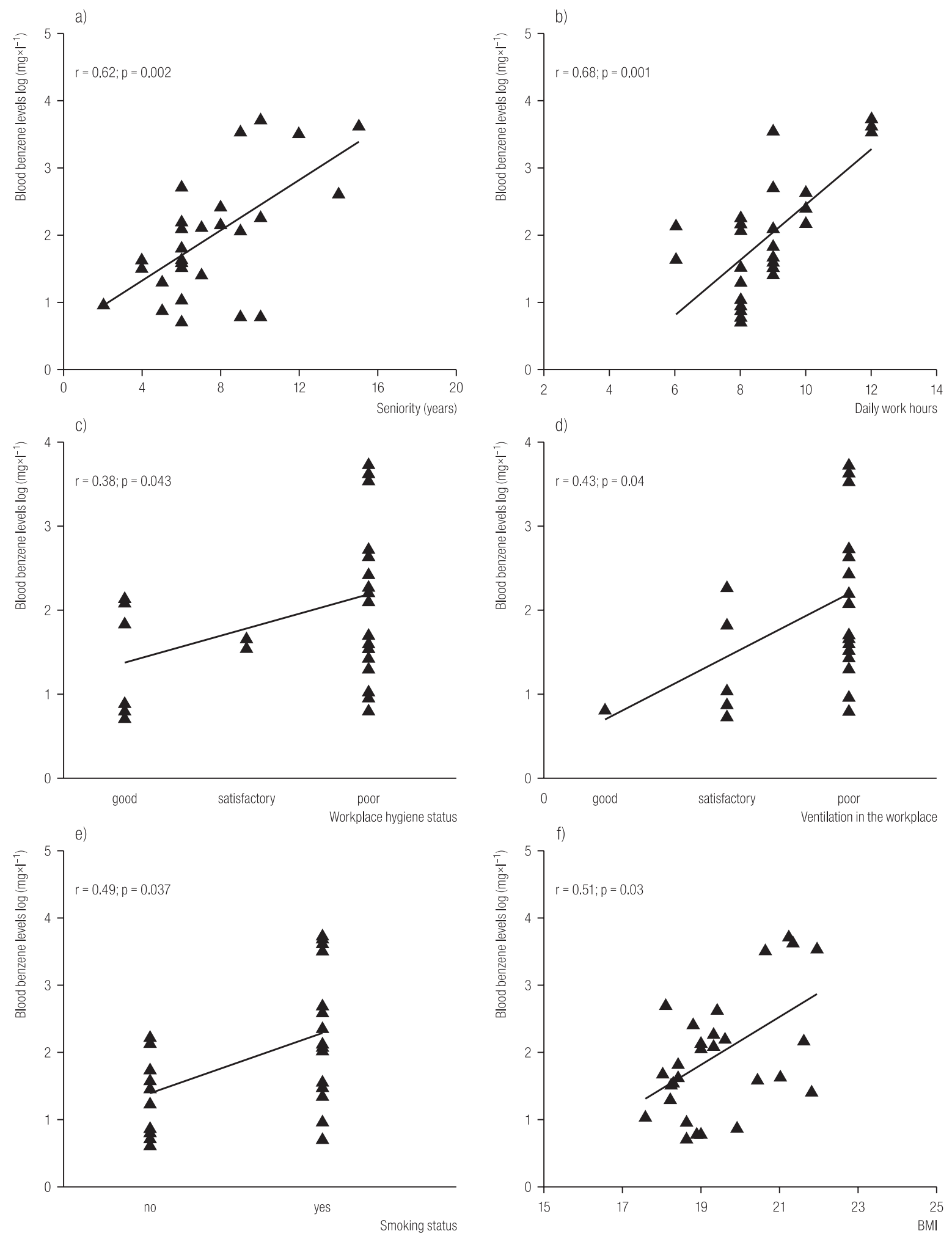

Fig. 1. Association between blood benzene levels (log-transformed) and variables of interests, i.e., a) work experience, b) working hours, c) workplace hygiene status, d) ventilation in the workplace, e) workers' smoking status, and f) body mass index (BMI) 


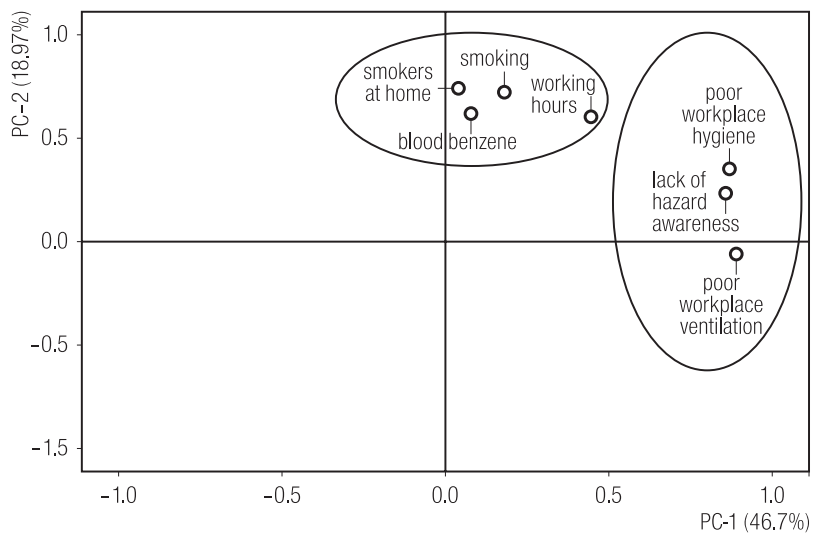

$\mathrm{PC}$ - principle component.

Fig. 2. Loading plot for blood benzene and occupational characteristics

absorption is directly proportional to the concentration of substances on the skin. Manufacturing areas and service sectors, like PNs, degreasers, are those fields where the likelihood of dermal exposure is greater [17]. Apart from these facts, we also analyzed the contribution of environmental determinants on which not much information is available in the previous literature; therefore we discussed these factors in detail (Figure 3).

Our results are also confounded by smoking behavior of workers, because it is well known that apart from gasoline

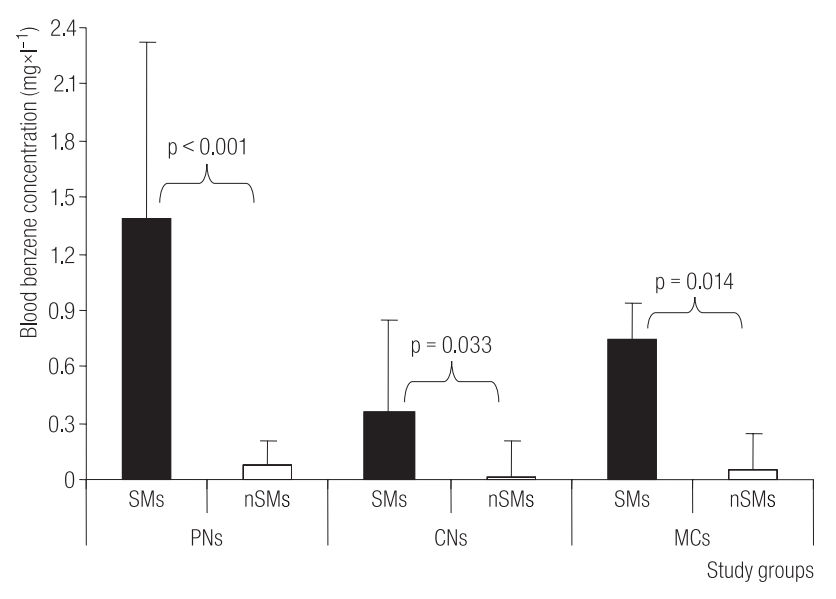

Abbreviations as in Table 1.

Fig. 3. Comparison for blood benzene concentrations among smokers (SMs) and non-smokers (nSMs) in each studied group and petroleum exposure, smoking also enhances the risk of exposure [16]. Environmental exposure to benzene is also a cause of concern to local community. According to our findings, blood benzene levels were much lower in nSMs among the CNs group than SMs. Smoking may therefore be a significant direct cause of exposure to benzene and studies have shown that SMs retained more blood benzene; consequent blood-air association is also threatening to the general population [15].

As mentioned earlier, the workplace parameters are worth monitoring as many cases of exposure are related with workplace ambience. For instance poor ventilation, which may be defined as a low level of exhaust system or no exhaust system at all, and relying merely upon natural ventilation [18] can enhance exposure significantly. A good source of ventilation in the workplace can thus ensure lower exposure to organic solvents.

In our study, several deficiencies were observed in the ventilation system in workplaces, and we also noticed that most of the visited painting sites were either adjacent to or within auto-repair stations, which possibly enhanced exposure to inhalable aerosol, although most of spray painting is carried out by keeping the minimal contact of the body parts with the cars. However, the level of airborne chemicals always remains high during the whole phase of a painting shift. A positive correlation $(\mathrm{r}=0.42)$ of our log-transformed data (Figure 1) with poor ventilation status gives us a clear association of the aforementioned scenario and a picture of expected future risk.

The lack of awareness among workers concerning the proper handling of chemicals coupled with poor ventilation in the workplaces increased the chances of benzene body burden manifold. The benzene concentration (and that of some other aromatic compounds) is more likely to get increased in blood of spray PNs, which seems apparent from our analysis. The cluster of items regarding component 1 of PCA represents a definite role of poor workplace ambience in terms of substandard hygiene in association with prolonged work 
hours and smoking as probable causes of rising blood benzene concentration of workers. The prevailing risk factors identified in PCA demand proper ventilation in workplaces as immediate intervention. In this context, the presence of open windows could prove substantially useful and this could be further improved by mechanical exhaust systems [8]. According to the Environmental Protection Agency [19], chemicals like benzene at painting booths should be monitored for keeping exposure within minimum limits. In this study, we found no rules and regulations regarding workers' safety being practiced at all sites visited. In addition, poor ventilation further aggravated the working conditions to a much lower level than standard hygiene environment. Our results showed that workplace hygiene is worth relating with the extent of exposure, as chemical residues that settle down or spills directly into workplace surroundings smear floor and furniture, etc., and if no proper maintenance is done to restore hygiene and tidiness in the workplace, it will become a long-term source of exposure. Low level air circulations contribute to humid ambience, and thus the airborne ratio of contaminants may get heavily increased.

According to the Health and Safety Executive [9], workplace hygiene is an important determinant of exposure. Not only the overall workplace cleanliness, but that of workplace furniture should also be properly maintained. Similarly, the surface of floors, walls and ceilings must be kept free from residues and waste by proper maintenance. The use of waste storage receptacle must also be kept in practice in workplaces, since it helps in improving the hygiene in the workplace [9]. Our visited workplaces had worse conditions regarding workplace hygiene. The present results reveal a potential higher exposure from ambient environment, as they showed overall poor hygiene (being worse at the painting sites) with higher levels of chemical residues in the surroundings. The results also showed a positive correlation of blood benzene levels with the prevalence of poor hygiene in the workplace $(r=0.38)$.
In addition to this, workplaces should have enough space for adequate seating and free movement of workers and also for their swift reaction in case of emergency [9].

A difference between the exposed and un-exposed groups revealed a strong correlation of blood benzene levels with daily working hours and work experience (log-transformed data, $r=0.68$ and $r=0.62$, respectively). The stepwise logistic regression analysis showed that every hour spent in such exposed sites significantly predicts the blood benzene level, and contributed to 0.23 units blood benzene concentration during each working hour while keeping other factors constant (Table 3).

Table 3. Stepwise linear regression analysis of blood benzene (dependent variable) and working hours (independent predictor)

\begin{tabular}{lccccc}
\hline \multicolumn{1}{c}{ Predictor } & B & SE of $\beta$ & $\beta$ & $95 \%$ CI for B \\
\hline Constant & 1.34 & 0.450 & - & 0.44 & 2.24 \\
Daily working hours & 0.23 & 0.054 & $0.48^{*}$ & 0.12 & 0.33 \\
\hline
\end{tabular}

SE - standard error; CI - confidence interval.

Dependent variable - benzene concentrations in blood.

$\mathrm{R}^{2}=0.24 ;$ Adjusted $\mathrm{R}^{2}=0.23 ; \mathrm{F}(1,58)=18.25$.

$* \mathrm{p}=0.004$.

According to Wan et al. [20], BMI and the duration of exposure are among those factors which may impact the prognosis of chronic benzene poisoning in genetically susceptible persons. Lin et al. [21] found in his study that the blood-air association with benzene and other related derivatives are influenced by smoking, age and also by BMI. Therefore, this study shows that the blood level of xenobiotics is influenced by a number of factors related with the occupational environment.

\section{CONCLUSIONS}

This study highlights the issue of benzene exposure in $\mathrm{Pa}$ kistan for the 1st time, concluding that exposure of PNs to benzene is highly influenced by the workplace ambience and the lack of hazard awareness and risk perception by 
workers in the workplaces. Due to poor air circulation in the workplace surroundings, and no use of self-protecting equipment on the part of the workers, the exposure risk via dermal and inhalation routes remains high. In addition, the exposure to chemicals like benzene and lead is enhanced by active and/or passive smoking. In countries like Pakistan, there is a dire need to create awareness among workers regarding the hazards associated with smoking in such workplaces and to ensure that the workers are well equipped with self-protecting equipments, especially in chemicals-influenced workplaces.

\section{REFERENCES}

1. Kamal A, Malik RN, Fatima N, Rashid A. Chemical exposure in occupational settings and related health risks: A neglected area of research in Pakistan. Environ Toxicol Pharmacol. 2012;34(1):46-58, http://dx.doi.org/10.1016/j.etap. 2012.02.009.

2. Kamal A, Qayyum M, Cheema IU, Rashid A. Biological monitoring of blood naphthalene level as a marker of occupational xposure to PAHs among car-mechanics and spray painters in Rawalpindi. BMC Public Health. 2011;11:467, http://dx.doi.org/10.1186/1471-2458-11-467.

3. Kamal A, Malik RN. Hematological evidence of occupational exposure to chemicals and other factors among autorepair workers in Rawalpindi, Pakistan. Osong Pub Health Res Persp. 2012;3(4):229-38, http://dx.doi.org/10.1016/j.phrp. 2012.10.003.

4. Vitali M, Ensabellal F, Stella D, Guidotti M. Exposure to organic solvents among handicraft car PNs: A pilot study in Italy. Ind Health. 2006;44:310-7, http://dx.doi.org/10.2486/ indhealth.44.310.

5. Karakitsios SP, Delis VK, Kassomenos PA, Pilidis GA. Contribution to ambient benzene concentrations in the vicinity of petrol stations: Estimation of the associated health risk. Atmosph Environ. 2007;41:1889-902, http://dx.doi.org/10. 1016/j.atmosenv.2006.10.052.
6. Kang SK, Lee MY, Kim TK, Lee JO, Ahn YS. Occupational exposure to benzene in South Korea Chem Biol Interact. 2005;153-4:65-74, http://dx.doi.org/10.1016/j.cbi. 2005.03.011.

7. Figa-Talamanca I, Salera EA. Exposure to benzene among workers in a petroleum transport company. J Occup Health. 2001;43:53-5, http://dx.doi.org/10.1539/joh.43.53.

8. Kalnas J, Teitelbaum DT. Dermal absorption of benzene: Implications for work practices and regulations. Int J Occup Environ Health. 2000;6(2):114-21, http://dx.doi.org/10.1179/ oeh.2000.6.2.114.

9. Health and Safety Executive. Workplace health, safety and welfare: A short guide for managers INDG244(rev2) [Internet]. HSE; 2000 [cited 2014 Jan 23]. 2 p. Available from: www.hse.gov.uk/pubns/indg244.pdf.

10. Lee CC, Lin WT, Liao PC, Su HJ, Chen HL. High average daily intake of PCDD/Fs and serum levels in residents living near a deserted factory producing pentachlorophenol (PCP) in Taiwan: Influence of contaminated fish consumption. Environ Pollut. 2006;141:381-6, http://dx.doi.org/ 10.1016/j.envpol.2005.08.032.

11. Garg P, Dubey R, editors. Hazards identification and control measures in chemical (industrial) workplaces; industrial disaster risk managment, Theme-3. Capacity Development Programme for industrial Disaster Risk Management (iDRM) inWEnt-gtz-ASEM, Germany division of environmental energy and water [cited 2010 May 20]. Available from: http://www.dmibhopal.nic.in.

12. Hoet P, de Smedt E, Ferrari M, Imbriani M, Maestri L, Negri $\mathrm{S}$, et al. Evaluation of urinary biomarkers of exposure to benzene: Correlation with blood benzene and in influence of confounding factors. Int Arch Occup Environ Health. 2009;82:985-95, http://dx.doi.org/10.1007/s00420-008-0381-6.

13. Tunsaringkarn T, Ketkaew P, Suwansaksri J, Siriwong W, Rungsiyothin A, Zapuang K, et al. Chromosomal damage risk assessment to benzene exposure among gasoline station workers in Bangkok metropolitan, Thailand. J Environ Earth Sci. 2011;1(2):37-44. 
14. Al-Daghri N. Serum polycyclic aromatic hydrocarbons among children with and without asthma: Correlation to environmental and dietary factors. Int J Occup Med Environ Health. 2008;21:211-7, http://dx.doi.org/10.2478/v10001-008-0021-0.

15. Kang S-K, Lee M-Y, Kim T-K, Lee J-O, Ahn YS. Occupational exposure to benzene in South Korea. Chem Biol Interact. 2005;153-4:65-74, http://dx.doi.org/10.1016/j.cbi. 2005.03.011.

16. Weisel CP. Benzene exposure: An overview of monitoring methods and their findings. Chem Biol Interact. 2010; 184(1-2):58-66, http://dx.doi.org/10.1016/j.cbi.2009.12.030.

17. Semple S. Dermal exposure to chemicals in the workplace: Just how important is skin absorption. Occup Environ Med. 2004;61:376-82, http://dx.doi.org/10.1136/oem.2003.010645.

18. Liu H, Liang Y, Bowes YS, Xu H, Zhou Y, Armstrong TW, et al. Benzene exposure in industries using or manufacturing paint in China: A literature review, 1956-2005. J Occup Environ Hyg. 2009;6:659-70, http:// dx.doi.org/10.1080/15459620903249646.

19. Environmental Protection Agency. Guideline: Spray painting booths-control of air and noise emissions (June 2007). EPA 100/07: Australian guideline replacement of earlier version.

20. Wan JX, Zhang ZB, Guan JR, Cao DZ, Ye R, Jin XP, et al. Genetic polymorphism of toxicant-metabolizing enzymes and prognosis of Chinese workers with chronic benzene poisoning. Ann NY Acad Sci. 2006;1076:129-36, http://dx.doi.org/10.1196/annals.1371.041.

21. Lin YS, Egeghy PP, Rappaport SM. Relationships between levels of volatile organic compounds in air and blood from the general population. J Expos Sci Environ Epidemiol. 2008;18(4):421-9, http://dx.doi.org/10.1038/sj.jes.7500635.

This work is available in Open Access model and licensed under a Creative Commons Attribution-NonCommercial 3.0 Poland License - http://creativecommons.org/ licenses/by-nc/3.0/pl/deed.en. 